OPEN ACCESS

Edited by:

Antonino Musolino,

University of Parma, Italy

Reviewed by:

Marco Invernizzi,

University of Eastern Piedmont, Italy Laura Cortesi,

University Hospital of Modena, Italy

${ }^{*}$ Correspondence: Ming-Hsin Yeh

breast5321@gmail.com

${ }^{\dagger}$ These authors have contributed equally to this work

Specialty section: This article was submitted to

Breast Cancer, a section of the journal

Frontiers in Oncology

Received: 12 August 2021 Accepted: 20 September 2021 Published: 11 October 2021

Citation:

Liu H-P, Wei JC-C, Yip H-T and

Yeh M-H (2021) Association of Insomnia, Depressive Disorders, and Mood Disorders as Risk Factors With

Breast Cancer: A Nationwide Population-Based Cohort Study of 232,108 Women in Taiwan

Front. Oncol. 11:757626. doi: 10.3389/fonc.2021.757626

\section{Association of Insomnia, Depressive Disorders, and Mood Disorders as Risk Factors With Breast Cancer: A Nationwide Population-Based Cohort Study of 232,108 Women in Taiwan}

\author{
Hui-Pu Liu ${ }^{1 \dagger}$, James Cheng-Chung Wei ${ }^{2,3,4 \dagger}$, Hei-Tung Yip ${ }^{5}$ and Ming-Hsin Yeh ${ }^{3,6 *}$
}

${ }^{1}$ Department of General Surgery, Kaohsiung Armed Forces General Hospital, Kaohsiung, Taiwan, ${ }^{2}$ Department of Allergy, Immunology \& Rheumatology, Chung Shan Medical University Hospital, Taichung, Taiwan, ${ }^{3}$ Institute of Medicine, College of Medicine, Chung Shan Medical University, Taichung, Taiwan, ${ }^{4}$ Graduate Institute of Integrated Medicine, China Medical University, Taichung, Taiwan, ${ }^{5}$ Management Office for Health Data, Clinical Trial Research Center, China Medical University Hospital, Taichung, Taiwan, ${ }^{6}$ Department of Surgery, Chung Shan Medical University Hospital, Taichung, Taiwan

Background: Insomnia, depressive disorders, and to a more general view, mood disorders are raising people's concerns and causing disability of life. Herein, we try to seek the association of such illnesses with subsequent breast cancer.

Methods: This population-based, retrospective cohort study used data from the Taiwan National Health Insurance Research Database. This study included 232,108 women diagnosed with insomnia, depressive disorders, and mood disorders from January 1 , 2000 to December 31, 2013. Physician diagnosed insomnia, depressive disorders, or mood disorders using outpatient and inpatient records before diagnosis of breast cancer. Cox proportional hazards regression analysis is adjusted for women with insomnia, depressive disorders, mood disorders, and other factors like insured amount, urbanization, and comorbidities such as having subsequent breast cancer.

Results: Sleep medication was associated with a significantly increased incidence rate of breast cancer (aHR $=1.23(95 \% \mathrm{Cl}=1.13,1.35), p<0.001)$. Insomnia was associated with significant increased hazard of breast cancer (aHR $=1.16(95 \% \mathrm{Cl}=1.07,1.27)$, $p<0.001$ ). Annual insured amount $>20,000$ (TWD), high urbanization area, and hyperlipidemia were associated with increased hazard of breast cancer (aHR $=1.13$ $(95 \% \mathrm{Cl}=1.01,1.27), p=0.04 ; \mathrm{aHR}=1.41(95 \% \mathrm{Cl}=1.17,1.71), p<0.001 ; \mathrm{aHR}=1.14$ $995 \% \mathrm{Cl}=1.02,1.29), p=0.02$, respectively). There was a positive correlation between depressive disorders and increased incidence rate of breast cancer but not statistically significant $(\mathrm{aHR}=1.11(95 \% \mathrm{Cl}=0.99,1.25), p=0.08)$. Mood disorders were not associated with increased hazard $(\mathrm{aHR}=1.11(95 \% \mathrm{Cl}=0.91,1.34), p=0.31)$. 
Conclusion: In this study, women with insomnia had increased risk of breast cancer, particularly those in high urbanization or with high insured amounts. Sleep medication (benzodiazepine (BZD) or non-BZD) and hyperlipidemia were independently associated with a higher hazard ratio of breast cancer. Insomnia along with sleep medication did not yield more hazards than each alone. Mood disorders appeared to be not associated with subsequent breast cancer. However, depressive disorders, the subgroups of mood disorders, could possibly increase the incidence rate of breast cancer though not statistically significant.

Keywords: breast cancer, depressive disorders, mood disorders, insomnia, sleeping medication, hyperlipidemia

\section{INTRODUCTION}

Breast cancer, the leading cause of cancer death in women, is drawing more and more attention in health issues universally. There are more than 2 million women with newly diagnosed breast cancer every year globally (1). In Taiwan, 13,965 new cases of breast cancer have been reported in 2017, being the most commonly diagnosed cancer in women: it can be estimated that nearly $27 \%$ of cancer cases in women is represented by breast cancer. Breast cancer is the most frequently diagnosed cancer and second most common cause of cancer death in the USA (2), and it is the principal cause of death in women aged 40 to 49 years; in this period, women are in transition of perimenopause and menopause.

Women may experience sleep disturbance, depression, and anxiety during perimenopause and menopause transition due to physiologic changes in responsiveness to gonadotropins with wide variation of hormone level (3). In the late perimenopausal transition lasting 1 to 3 years, most women will encounter amenorrhea for longer than 2 months and often suffer from vasomotor symptoms; during this period and early menopause, FSH level continue to rise while estradiol (E2) level is declining. It is not until 2 years after menopause that the hormone levels remain steady (4). These symptoms due to estrogen decline raise our concern for women's health about mental illness.

Impairment of cognitive function and affective function after diagnosis of breast cancer were reported (5), and alteration of hippocampus like deformation or volume loss were also found after major types of treatments. Some pivotal studies aimed at the survivorship of returning the quality of life to the status before diagnosis or even better (6). Breast cancer experience could have an impact on physical and psychosocial alterations such as increased risk of depression, anxiety, and intrusive thought, especially in younger patients. Disruption of body imagerelated (hair loss, weight gain, aesthetics, etc.) distress could be alleviated via psychological intervention $(7,8)$. Breast cancerrelated fatigue is also a major issue influencing quality of life, and some rehabilitation protocols like aerobic exercise could help (9). Several studies were focused on prevalence of mental illness during surgical intervention or medical treatment after diagnosing breast cancer since many cases of breast cancer are associated with physical disability and a poor quality of life after their breast cancer diagnosis with symptoms of fatigue, depression, and anxiety (10). However, herein, we focused on the association of insomnia, depressive disorders, or mood disorders with subsequent breast cancer in women.

Insomnia, one of the most common sleep disorders, affects approximately $6 \%-30 \%$ of the overall population (11-13). Emerging evidence suggests that insomnia is independently associated with psychiatric diseases (14), impaired healthrelated quality of life (15), and increased risks of hormonerelated diseases (16) such as cancers (17).

The mood disorders are currently confined to disorders in which the mood is depressed or elevated. Mood disorders have once been interchangeably viewed as "affective disorder", a term which is still used frequently. Some studies have revealed that depressive disorders are related to substantial mortality, some comorbidities, and disabilities $(18,19)$.

Globally, around $10.7 \%$ of disability can be attributed to unipolar major depression. According to Joyce (20), unipolar major depression accounts for nearly $20 \%$ of disease burden in women aged 15 to 44 years old in developed countries. Therefore, we also investigated the association of some variants like insured amount, level of urbanization, and residential location in representatives of socioeconomic status, with breast cancer.

\section{METHODS}

\section{Data Sources/Measurement}

The Taiwan National Health Insurance Research Database (NHIRD) was established in 1995. The compulsory National Health Insurance program covered more than 99\% of Taiwan residents, and their original claim data were stored in NHIRD. We utilized and analyzed the Longitudinal Health Insurance Data (LHID), which contains data of one million random selected insureds. The medical data included outpatient and inpatient records, the medication used, and treatment received. The identification number was encoded for protecting privacy problems. The diagnostic codes were recorded based on the International Classification of Disease, Ninth Revision, Clinical Modification (ICD-9-CM). This study was approved by the ethical review board of the China Medical University Hospital [CMUH104-REC2-115(AR-4)]. 


\section{Study Cohort}

In this study, we conducted three cohort studies which are shown in Figure 1. The first cohort was an insomnia cohort. Patients who were newly diagnosed with insomnia (ICD-9-CM codes 307.41, $307.42,307.49,780.50,780.52,780.55,780.56$, and 780.59) were the cases in this cohort. Those without insomnia were the controls. For the second cohort, the case cohort consisted of the patients with depressive disorders (ICD-9-CM codes 296.2, 296.3, 298.0, 300.4, 311, and V79.0) and the control cohort were patients never diagnosed with depressive disorders. The last cohort recruited patients with mood disorders (ICD-9-CM codes 296.0-296.7) as the case cohort and patients without mood disorders as the control cohort. The first diagnosis was the index date for case cohort and a random date between 2000 and 2012 was assigned to controls as the index date. The study period for all cohorts was 2000 to 2013 . We excluded patients who were male, aged below 20 and diagnosed with breast cancer before the index date. Control patients were matched to case patients according to age, insured amount, urbanization level, residential location, and index year in a 1:1 ratio for the insomnia cohort and in 1:4 ratio for depressive disorder and mood disorder cohorts.

\section{Primary Outcome}

Breast cancer (ICD-9-CM code 174) was the main outcome in this study. Patients who received the Major Illness or Injury Certificate of breast cancer were defined as the outcome. We followed up the participants from the index date to the development of breast cancer; withdraw from the NHI program or the end of the study, Dec. 31, 2013.

\section{Variables}

Demographic variables included age, insured amount, urbanization, and residential location. Age was divided into four groups: $20-30$ years old; $31-40$ years old; $41-50$ years old; and $>50$ years old. The related comorbidities included chronic obstructive pulmonary disease (COPD) (ICD-9-CM codes 491, 492, and 496), hypertension (HTN) (ICD-9-CM codes 401-405), diabetes mellitus (DM) (ICD-9-CM code 250), chronic kidney disease (CKD) (ICD-9-CM code 585), and hyperlipidemia (ICD9-CM code 272). We also considered the use of sleeping pills potential confounders.

\section{Statistical Methods}

The difference of the categorical variables and continuous variables in case cohort and the control cohort were expressed by standard mean difference (SMD). SMD of less than 0.1 means the difference can be neglected. The hazard ratio (HR) and 95\% confidence interval (CI) were calculated by the Cox proportional model. The Kaplan-Meier method was applied to obtain the cumulative incidence curves and tested by the Log-rank test. All statistical analysis was performed by software SAS (version 9.4 for Windows; SAS Institute, Inc., Cary, NC, USA). A p-value of less than 0.05 was the statistically significant level.

\section{RESULTS}

\section{Patient Characteristics With and Without Insomnia}

Baseline characteristics of the 116,009 women with noninsomnia and 116,009 women with insomnia in this cohort (mean [SD] age: 47.8 [16.4] in noninsomnia group and 47.6 [15.7] in insomnia group) are provided in Table 1. The insured amount within 10,000-20,000 was predominant in noninsomnia [36\%] and insomnia [38\%]. Patients were mainly in highly urbanized areas in the noninsomnia $(69,759[60 \%])$ and insomnia $(70,372$ [61\%]) groups. The majority of patients (noninsomnia $(52,296$ [45\%]) and insomnia $(51,792[45 \%]))$ resided in the northern area of Taiwan. Compared with patients with noninsomnia, those with insomnia had more comorbidities including COPD

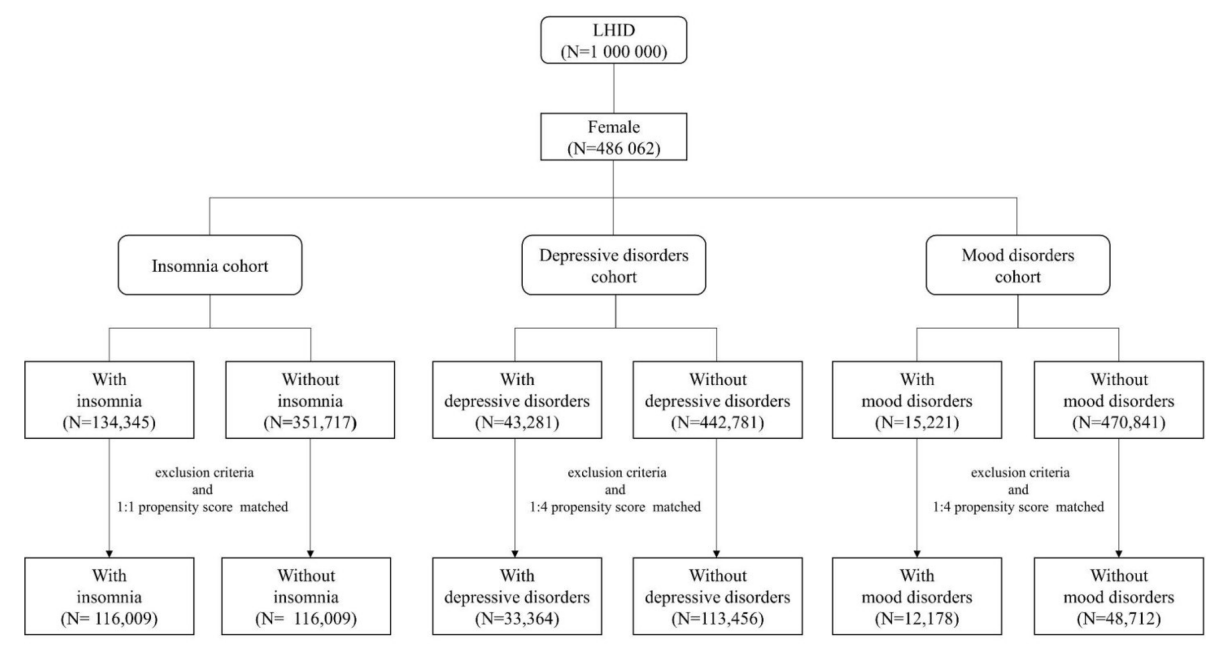

FIGURE 1 | The flowchart of the three cohorts in this study: insomnia cohort, depressive disorder cohort, and mood disorder cohort. 
TABLE 1 | The baseline characteristics of patients with and without insomnia.

\begin{tabular}{|c|c|c|c|c|c|}
\hline \multirow[t]{3}{*}{ Variable } & \multirow{2}{*}{\multicolumn{2}{|c|}{$\begin{array}{l}\text { Noninsomnia } \\
N=116,009\end{array}$}} & \multirow{2}{*}{\multicolumn{2}{|c|}{$\begin{array}{c}\text { Insomnia } \\
N=116,009\end{array}$}} & \multirow[t]{3}{*}{ SMD } \\
\hline & & & & & \\
\hline & $n$ & $\%$ & $n$ & $\%$ & \\
\hline \multicolumn{6}{|l|}{ Age (year) } \\
\hline 20-30 & 17,695 & $15 \%$ & 17,381 & $15 \%$ & 0.008 \\
\hline $30-40$ & 23,150 & $20 \%$ & 22,677 & $20 \%$ & 0.010 \\
\hline $40-50$ & 27,524 & $24 \%$ & 27,708 & $24 \%$ & 0.004 \\
\hline$>50$ & 47,640 & $41 \%$ & 48,243 & $42 \%$ & 0.001 \\
\hline Mean (SD) & 47.8 & $(16.4)$ & 47.6 & $(15.7)$ & 0.011 \\
\hline \multicolumn{6}{|c|}{ Insured amount (TWD) } \\
\hline$\leq 10,000$ & 40,126 & $35 \%$ & 39,306 & $34 \%$ & 0.015 \\
\hline $10,000-20,000$ & 42,241 & $36 \%$ & 43,756 & $38 \%$ & 0.027 \\
\hline$>20,000$ & 33,642 & $29 \%$ & 32,947 & $28 \%$ & 0.013 \\
\hline \multicolumn{6}{|l|}{ Urbanization } \\
\hline Low & 9,136 & $8 \%$ & 8,827 & $8 \%$ & 0.010 \\
\hline Medium & 37,114 & $32 \%$ & 36,810 & $32 \%$ & 0.006 \\
\hline High & 69,759 & $60 \%$ & 70,372 & $61 \%$ & 0.011 \\
\hline \multicolumn{6}{|l|}{ Residential location } \\
\hline Northern & 52,296 & $45 \%$ & 51,792 & $45 \%$ & 0.009 \\
\hline Central & 28,835 & $25 \%$ & 31,369 & $27 \%$ & 0.050 \\
\hline Southern & 13,846 & $12 \%$ & 12,882 & $11 \%$ & 0.026 \\
\hline Eastern & 20,790 & $18 \%$ & 19,792 & $17 \%$ & 0.023 \\
\hline Others & 242 & $0.21 \%$ & 174 & $0.15 \%$ & 0.014 \\
\hline \multicolumn{6}{|l|}{ Comorbidities } \\
\hline COPD & 18,879 & $16 \%$ & 28,271 & $24 \%$ & 0.202 \\
\hline HTN & 24,046 & $21 \%$ & 30,609 & $26 \%$ & 0.134 \\
\hline DM & 11,910 & $10 \%$ & 14,486 & $12 \%$ & 0.070 \\
\hline CKD & 7,558 & $7 \%$ & 11,403 & $10 \%$ & 0.121 \\
\hline Hyperlipidemia & 16,296 & $14 \%$ & 22,425 & $19 \%$ & 0.142 \\
\hline \multicolumn{6}{|l|}{ Medication } \\
\hline Sleep pills & 21,999 & $19 \%$ & 34,612 & $30 \%$ & 0.255 \\
\hline
\end{tabular}

COPD, chronic obstruction pulmonary disease; HTN, hypertension; DM, diabetes mellitus; $C K D$, chronic kidney disease; SMD, standard mean difference (less than 0.1 means no difference).

$(18,879$ [16\%] vs. $28,271[24 \%]), \operatorname{HTN}(24,046$ [21\%] vs. 30,609 [26\%]), CKD (7,558 [7\%] vs. 11,403 [10\%]), and hyperlipidemia $(16,296$ [14\%] vs. 22,425 [19\%]) (SMD >0.1 for all). Compared with patients with noninsomnia, those with insomnia had more sleeping pills $(21,999$ [19\%] vs. 34,612 [30\%]) (SMD >0.1).

\section{With and Without Depressive Disorders}

Table 2 presents the baseline characteristics of 33,364 women with depressive disorders and 133,456 women without depressive disorders (mean [SD] age: 48.1 [16.9] in nondepressive disorder group and 48.2 [16.8] in depressive disorder group). Most patients were in highly urbanized areas $(83,346$ [62\%]) for the control group and 20,835 [62\%] for depressive disorders). Patients with depressive disorders had more comorbidities including COPD (25,314 [19\%] vs. 9,200 [28\%]), HTN (31,182 [23\%] vs. 10,350 [31\%]), DM (15,243 [11\%] vs. 5,280 [16\%]), CKD (10,314 [8\%] vs. 4,094 [12\%]), and hyperlipidemia $(21,846$ [16\%] vs. 7,866 [24\%]) $(\mathrm{SMD}>0.1)$ than those without depressive disorders.

With and Without Mood Disorders

As shown in Table 3, 12,178 women with mood disorders and 48,712 patients without mood disorders (mean [SD] age: 46.6
TABLE 2 | The baseline characteristics of patients with and without depressive disorder.

\begin{tabular}{|c|c|c|c|c|c|}
\hline \multirow[t]{3}{*}{ Variable } & \multirow{2}{*}{\multicolumn{2}{|c|}{$\begin{array}{c}\begin{array}{c}\text { Nondepressive } \\
\text { disorders }\end{array} \\
N=133,456\end{array}$}} & \multirow{2}{*}{\multicolumn{2}{|c|}{$\begin{array}{c}\text { Depressive } \\
\text { disorders } \\
N=33,364\end{array}$}} & \multirow[t]{3}{*}{ SMD } \\
\hline & & & & & \\
\hline & $n$ & $\%$ & $n$ & $\%$ & \\
\hline \multicolumn{6}{|l|}{ Age (year) } \\
\hline $20-30$ & 21,988 & $16 \%$ & 5,484 & $16 \%$ & 0.001 \\
\hline $30-40$ & 25,693 & $19 \%$ & 6,390 & $19 \%$ & 0.003 \\
\hline $40-50$ & 28,570 & $21 \%$ & 7,057 & $21 \%$ & 0.006 \\
\hline$>50$ & 57,205 & $43 \%$ & 14,433 & $43 \%$ & 0.008 \\
\hline Mean (SD) & 48.1 & (16.9) & 48.2 & (16.8) & 0.005 \\
\hline \multicolumn{6}{|c|}{ Insured amount (TWD) } \\
\hline$\leq 10,000$ & 48,189 & $36 \%$ & 12,013 & $36 \%$ & 0.002 \\
\hline $10,000-$ & 49,638 & $37 \%$ & 12,494 & $37 \%$ & 0.005 \\
\hline \multicolumn{6}{|l|}{20,000} \\
\hline$>20,000$ & 35,629 & $27 \%$ & 8,857 & $27 \%$ & 0.003 \\
\hline \multicolumn{6}{|l|}{ Urbanization } \\
\hline Low & 9,566 & $7 \%$ & 2,577 & $8 \%$ & 0.021 \\
\hline Medium & 40,544 & $30 \%$ & 9,952 & $30 \%$ & 0.012 \\
\hline High & 83,346 & $62 \%$ & 20,835 & $62 \%$ & $<0.001$ \\
\hline \multicolumn{6}{|c|}{ Residential location } \\
\hline Northern & 61,277 & $46 \%$ & 15,248 & $46 \%$ & 0.004 \\
\hline Central & 30,909 & $23 \%$ & 7,700 & $23 \%$ & 0.002 \\
\hline Southern & 15,474 & $12 \%$ & 3,886 & $12 \%$ & 0.002 \\
\hline Eastern & 25,599 & $19 \%$ & 6,479 & $19 \%$ & 0.006 \\
\hline Others & 197 & $0.15 \%$ & 51 & $0.15 \%$ & 0.001 \\
\hline \multicolumn{6}{|l|}{ Comorbidities } \\
\hline COPD & 25,314 & $19 \%$ & 9,200 & $28 \%$ & 0.205 \\
\hline HTN & 31,182 & $23 \%$ & 10,350 & $31 \%$ & 0.173 \\
\hline DM & 15,243 & $11 \%$ & 5,280 & $16 \%$ & 0.129 \\
\hline CKD & 10,314 & $8 \%$ & 4,094 & $12 \%$ & 0.152 \\
\hline Hyperlipidemia & 21,846 & $16 \%$ & 7,866 & $24 \%$ & 0.181 \\
\hline \multicolumn{6}{|l|}{ Medication } \\
\hline Sleep pills & 32,305 & $24 \%$ & 8,250 & $25 \%$ & 0.012 \\
\hline
\end{tabular}

COPD, chronic obstruction pulmonary disease; HTN, hypertension; DM, diabetes mellitus; CKD, chronic kidney disease; SMD, standard mean difference (less than 0.1 means no difference).

[16.5\%] in nonmood disorder group and 46.6 [16.4\%] in depressive disorder group) are included. A higher proportion of comorbidities including COPD (9,165 [19\%] vs. 3,480 [29\%]), HTN $(10,710$ [22\%] vs. 3,645 [30\%]), DM (5,443 [11\%] vs. 1,971 [16\%]), $\operatorname{CKD}(3,661[8 \%]$ vs. 1,519 [12\%]), and hyperlipidemia $(7,874$ [16\%] vs. 2,842 [23\%]) were found in patient with mood disorders.

\section{The Incidence Rate and Hazard Ratios of Breast Cancer \\ With and Without Insomnia}

Table 4 shows that women with insomnia had increased breast cancer $(\mathrm{aHR}=1.16(95 \% \mathrm{CI}=1.07,1.27), p<0.001)$. The cumulative incidence of breast cancer in patients with and without insomnia is shown in Figure 2. Patients with sleep medication were associated with a significantly increased incidence rate of breast cancer $(\mathrm{aHR}=1.23(95 \% \mathrm{CI}=1.13$, 1.35 ), $p<0.001$ ). Annual insured amount $>20,000$ (TWD), high urbanization area, and hyperlipidemia were associated with increased hazard of breast cancer $(\mathrm{aHR}=1.13(95 \% \mathrm{CI}=1.01$, $1.27), p=0.04 ; \mathrm{aHR}=1.41(95 \% \mathrm{CI}=1.17,1.71), p<0.001$; $\mathrm{aHR}=1.14(95 \% \mathrm{CI}=1.02,1.29), p=0.02$, respectively) . 
TABLE 3 | The baseline characteristics of patients with and without mood disorders.

\begin{tabular}{|c|c|c|c|c|c|}
\hline \multirow[t]{3}{*}{ Variable } & \multirow{2}{*}{\multicolumn{2}{|c|}{$\begin{array}{c}\text { Nonmood disorders } \\
\qquad N=48,712\end{array}$}} & \multirow{2}{*}{\multicolumn{2}{|c|}{$\frac{\text { Mood disorders }}{N=12,178}$}} & \multirow[t]{3}{*}{ SMD } \\
\hline & & & & & \\
\hline & $n$ & $\%$ & $n$ & $\%$ & \\
\hline \multicolumn{6}{|l|}{ Age (year) } \\
\hline 20-30 & 8,954 & $18 \%$ & 2,238 & $18 \%$ & $<0.001$ \\
\hline $30-40$ & 10,295 & $21 \%$ & 2,565 & $21 \%$ & 0.002 \\
\hline $40-50$ & 10,320 & $21 \%$ & 2,576 & $21 \%$ & 0.001 \\
\hline$>50$ & 19,143 & $39 \%$ & 4,799 & $39 \%$ & 0.002 \\
\hline Mean (SD) & 46.6 & (16.5) & 46.6 & (16.4) & 0.002 \\
\hline \multicolumn{6}{|c|}{ Insured amount (TWD) } \\
\hline$\leq 10,000$ & 18,749 & $39 \%$ & 4,690 & $39 \%$ & $<0.001$ \\
\hline $10,000-20,000$ & 18,555 & $38 \%$ & 4,646 & $38 \%$ & 0.001 \\
\hline$>20,000$ & 11,408 & $23 \%$ & 2,842 & $23 \%$ & 0.002 \\
\hline \multicolumn{6}{|l|}{ Urbanization } \\
\hline Low & 3,329 & $7 \%$ & 871 & $7 \%$ & 0.012 \\
\hline Medium & 14,071 & $29 \%$ & 3,510 & $29 \%$ & 0.001 \\
\hline High & 31,312 & $64 \%$ & 7,797 & $64 \%$ & 0.005 \\
\hline \multicolumn{6}{|l|}{ Residential location } \\
\hline Northern & 23,031 & $47 \%$ & 5,756 & $47 \%$ & $<0.001$ \\
\hline Central & 10,815 & $22 \%$ & 2,700 & $22 \%$ & 0.001 \\
\hline Southern & 4,901 & $10 \%$ & 1,225 & $10 \%$ & $<0.001$ \\
\hline Eastern & 9,933 & $20 \%$ & 2,484 & $20 \%$ & $<0.001$ \\
\hline Others & 32 & $0.07 \%$ & 13 & $0.11 \%$ & 0.014 \\
\hline \multicolumn{6}{|l|}{ Comorbidities } \\
\hline COPD & 9,165 & $19 \%$ & 3,480 & $29 \%$ & 0.231 \\
\hline HTN & 10,710 & $22 \%$ & 3,645 & $30 \%$ & 0.182 \\
\hline DM & 5,443 & $11 \%$ & 1,971 & $16 \%$ & 0.146 \\
\hline CKD & 3,661 & $8 \%$ & 1,519 & $12 \%$ & 0.166 \\
\hline Hyperlipidemia & 7,874 & $16 \%$ & 2,842 & $23 \%$ & 0.181 \\
\hline \multicolumn{6}{|l|}{ Medication } \\
\hline Sleep pills & 11,665 & $24 \%$ & 2,367 & $19 \%$ & 0.110 \\
\hline
\end{tabular}

COPD, chronic obstruction pulmonary disease; HTN, hypertension; DM, diabetes mellitus; CKD, chronic kidney disease; SMD, standard mean difference (less than 0.1 means no difference).

\section{With and Without Depressive Disorders/Mood Disorders}

The depressive disorder- or mood disorder-related incidence rates and hazard ratio of breast cancer are shown in Tables 5 and $\mathbf{6}$, respectively. In Table 5, there was a positive correlation between depressive disorders and increased incidence rate of breast cancer, but it was not statistically significant $(\mathrm{aHR}=1.11$ (95\% CI $=0.99$, $1.25), p=0.08$ ). Patients with sleep medication were associated with a significantly increased incidence rate of breast cancer $(\mathrm{aHR}=1.39(95 \% \mathrm{CI}=1.26,1.54), p<0.001)$. High urbanization area and hyperlipidemia were associated with increased hazard of breast cancer $(\mathrm{aHR}=1.37$ (95\% CI $=1.10$, $1.71), p<0.01 ; \mathrm{aHR}=1.32(95 \% \mathrm{CI}=1.15,1.51), p<0.001$, respectively). In Table 6, the patients with mood disorders were not associated with increased hazard of breast cancer $(\mathrm{aHR}=1.11$ (95\% CI $=0.91,1.34), p=0.31$ ). Patients with sleep medication were associated with a significant increased incidence rate of breast cancer $(\mathrm{aHR}=1.53(95 \% \mathrm{CI}=1.30,1.80), p<0.001)$. Annual insured amount $>20,000$ (TWD) and hyperlipidemia were associated with increased hazard of breast cancer $(\mathrm{aHR}=1.24$ $(95 \% \mathrm{CI}=1.00,1.54), p<0.05 ; \mathrm{aHR}=1.33$ (95\% CI = 1.06, 1.66), $p<0.001$, respectively). Kaplan-Meier curves of breast cancer in the depressive disorder cohort and the mood disorder cohort are demonstrated in Figures 3 and 4, individually.

\section{The Association of Insomnia and Breast Cancer in Different Stratification}

Patients with insomnia along with annual insured amount of more than 20,000 (TWD) $(\mathrm{aHR}=1.27(95 \% \mathrm{CI}=1.10,1.46)$, $p<0.001)$ and high urbanization $(\mathrm{aHR}=1.23(95 \% \mathrm{CI}=1.11$, 1.37), $p<0.001$ ) were associated with significant increased hazard of breast cancer relative to those without insomnia, see Table 7. Insomnia patients with residential location in the northern area also increased the risk of breast cancer by 1.22 times $(95 \% \mathrm{CI}=1.08,1.38 ; p=0.001)$ compared with the control patients who lived in the northern area. Patients who had insomnia with sleep medication did not yield an increased hazard of breast cancer over those without insomnia.

\section{The Effect of Sleeping Pills on Breast Cancer in Insomnia Cohort}

The effect of sleeping pills on breast cancer is shown in Table 8. Either noninsomnia with sleeping pills $(\mathrm{aHR}=1.46(95 \%$ CI $=1.28,1.67), p<0.001)$, insomnia without sleeping pills $(\mathrm{aHR}=1.28(95 \% \mathrm{CI}=1.16,1.42), p<0.001)$, or insomnia with sleeping pills $(\mathrm{aHR}=1.43(95 \% \mathrm{CI}=1.27,1.61), p<0.001)$ was associated with significant increased hazard of breast cancer. However, insomnia combined with sleeping pills did not yield more hazard ratio than either insomnia or sleeping pills alone.

\section{DISCUSSION}

To our knowledge, the present analysis, which pooled data from the Taiwan National Health Insurance Research Database, is the largest study to evaluate breast cancer and insomnia, depressive disorders, and mood disorders. In this cohort study, women (>20 years old) with insomnia had $16 \%$ higher rates of breast cancer. We also found that sleep medication, high insured amount, highly urbanized areas, and hyperlipidemia were associated with significantly increased incidence rate of breast cancer. There was a positive correlation between depressive disorders and increased incidence rate of breast cancer, but it was not statistically significant. Mood disorders were not associated with increased hazard of breast cancer. In summary, the risk factors of breast cancer in our study were insomnia, sleep medication, high urbanization, high insured amount, and hyperlipidemia.

Several studies concerning insomnia were mainly focused on the relationship of patients with preexisting breast cancer, but insomnia as a risk factor for breast cancer among primarily cancer-free women were rarely investigated $(17,21)$. Shift work involving circadian disruption was classified as being a probable carcinogen to humans according to the World Health Organization's International Agency for Research on Cancer in 2007 (22). The likely underlying mechanisms could be disturbed sleep, exposure to light at night, and other lifestyle factors (2325). A positive correlation between circadian disruption and 
TABLE 4 | The incidence rates and hazard ratios of breast cancer in insomnia cohort.

\begin{tabular}{|c|c|c|c|c|c|}
\hline \multirow[t]{2}{*}{ Variable } & \multicolumn{3}{|c|}{ Breast cancer } & \multirow[t]{2}{*}{ cHR $(95 \% \mathrm{Cl})$} & \multirow[t]{2}{*}{$\mathrm{aHR}^{\mathrm{a}}(95 \% \mathrm{Cl})$} \\
\hline & $\mathbf{n}$ & PY & IR & & \\
\hline \multicolumn{6}{|l|}{ Insomnia } \\
\hline No & 1,023 & 874,576 & 1.17 & $1.00(-)$ & $1.00(-)$ \\
\hline Yes & 1,257 & 892,053 & 1.41 & $1.21(1.12,1.32)^{\star \star \star}$ & $1.16(1.07,1.27)^{\star \star \star}$ \\
\hline \multicolumn{6}{|l|}{ Age (year) } \\
\hline $20-30$ & 47 & 257,668 & 0.18 & $1.00(-)$ & $1.00(-)$ \\
\hline $30-40$ & 339 & 354,040 & 0.96 & $5.16(3.80,7.00)^{\star \star \star}$ & $4.80(3.52,6.54)^{\star \star \star}$ \\
\hline $40-50$ & 801 & 446,414 & 1.79 & $9.57(7.13,12.8)^{\star \star \star}$ & $8.64(6.39,11.7)^{\star \star \star}$ \\
\hline$>50$ & 1,093 & 708,507 & 1.54 & $8.28(6.18,11.1)^{\star \star \star}$ & $7.55(5.59,10.2)^{\star \star \star}$ \\
\hline \multicolumn{6}{|c|}{ Insured amount (TWD) } \\
\hline$\leq 10,000$ & 489 & 554,518 & 0.88 & $1.00(-)$ & $1.00(-)$ \\
\hline $10,000-20,000$ & 970 & 678,151 & 1.43 & $1.58(1.42,1.76)^{\star \star \star}$ & $1.10(0.99,1.23)$ \\
\hline$>20,000$ & 821 & 533,960 & 1.54 & $1.68(1.50,1.88)^{\star \star \star}$ & $1.13(1.01,1.27)^{\star}$ \\
\hline \multicolumn{6}{|l|}{ Urbanization } \\
\hline Low & 130 & 139,811 & 0.93 & $1.00(-)$ & $1.00(-)$ \\
\hline Medium & 678 & 565,687 & 1.20 & $1.31(1.09,1.59)^{\star \star}$ & $1.27(1.05,1.54)^{*}$ \\
\hline High & 1,472 & $1,061,131$ & 1.39 & $1.52(1.27,1.82)^{\star \star \star}$ & $1.41(1.17,1.71)^{\star \star \star}$ \\
\hline \multicolumn{6}{|l|}{ Residential location } \\
\hline Northern & 1,122 & 790,556 & 1.42 & $1.00(-)$ & $1.00(-)$ \\
\hline Central & 554 & 463,092 & 1.20 & $0.84(0.76,0.93)^{\star \star}$ & $0.95(0.85,1.06)$ \\
\hline Southern & 254 & 200,251 & 1.27 & $0.89(0.78,1.02)$ & $0.96(0.84,1.11)$ \\
\hline Eastern & 348 & 309,410 & 1.12 & $0.79(0.70,0.89)^{\star \star \star}$ & $0.86(0.76,0.97)^{\star}$ \\
\hline Others & 2 & 3,320 & 0.60 & $0.42(0.10,1.68)$ & $0.57(0.14,2.33)$ \\
\hline \multicolumn{6}{|l|}{ Comorbidities } \\
\hline \multicolumn{6}{|l|}{ COPD } \\
\hline No & 1,819 & $1,432,028$ & 1.27 & $1.00(-)$ & \\
\hline Yes & 461 & 334,601 & 1.38 & $1.10(1.00,1.22)$ & \\
\hline \multicolumn{6}{|l|}{ HTN } \\
\hline No & 1,676 & $1,373,140$ & 1.22 & $1.00(-)$ & $1.00(-)$ \\
\hline Yes & 604 & 393,490 & 1.53 & $1.27(1.16,1.39)^{\star \star \star}$ & $0.96(0.86,1.07)$ \\
\hline \multicolumn{6}{|l|}{ DM } \\
\hline No & 1,991 & $1,581,543$ & 1.26 & $1.00(-)$ & $1.00(-)$ \\
\hline Yes & 289 & 185,087 & 1.56 & $1.27(1.12,1.44)^{\star \star \star}$ & $1.00(0.88,1.15)$ \\
\hline \multicolumn{6}{|l|}{ CKD } \\
\hline No & 2,096 & $1,626,558$ & 1.29 & $1.00(-)$ & \\
\hline Yes & 184 & 140,072 & 1.31 & $1.02(0.88,1.19)$ & \\
\hline \multicolumn{6}{|l|}{ Hyperlipidemia } \\
\hline No & 1,826 & $1,493,915$ & 1.22 & $1.00(-)$ & $1.00(-)$ \\
\hline Yes & 454 & 272,715 & 1.66 & $1.40(1.27,1.56)^{\star \star \star}$ & $1.14(1.02,1.29)^{*}$ \\
\hline \multicolumn{6}{|l|}{ Medication } \\
\hline \multicolumn{6}{|l|}{ Sleep pills } \\
\hline No & 1,446 & $1,243,629$ & 1.16 & $1.00(-)$ & $1.00(-)$ \\
\hline Yes & 834 & 523,001 & 1.59 & $1.28(1.18,1.4)^{\star \star \star}$ & $1.23(1.13,1.35)^{\star \star \star}$ \\
\hline
\end{tabular}

${ }^{*} p$-value $<0.05 ;{ }^{* *} p$-value $<0.01 ;{ }^{* * *} p$-value $<0.001$.

PY, person-years; IR, incidence rate (per 1,000 person-years); CHR, crude hazard ratio; aHR, adjusted hazard ratio; COPD, chronic obstruction pulmonary disease; HTN, hypertension; DM, diabetes mellitus; CKD, chronic kidney disease.

${ }^{a}$ Adjusted by age, insured amount, HTN, DM, hyperlipidemia, and sleep pills.

breast cancer $(\mathrm{HR}=1.14(95 \% \mathrm{CI}=1.08,1.21))$ was proposed in a meta-analysis of 28 studies. Whereas, short sleep duration ( $<7 \mathrm{~h} /$ night) and dose-response association with sleep deficiency were not conclusive (26). Neither chronotype nor individual insomnia symptoms were strongly associated with breast cancer in evidence $(27,28)$. The relationship between insomnia and breast cancer could be understood via metabolic dysfunction as glucose homeostasis imbalance. Those with elevated blood glucose were related to decreased survival independent of comorbid diabetes mellitus (type 2) and body mass index (29, 30). According to Borniger et al., in a single nonmetastatic model of breast cancer, the underlying mechanism mediating cancerassociated metabolic changes and sleep disruption may be aberrant activity of wake-stabilizing hypocretin/orexin (HO) neuron (31).

Sleep medication, also called hypnotics, are mainly divided into benzodiazepines (BZDs) and nonbenzodiazepines (non-BZDs), and other miscellaneous types like gamma-aminobutyric acid agonist, melatonin receptor agonists, antihistamines, sedating antidepressant, and eugeroic drugs are not commonly administered (32). Both BZDs and non-BZDs (zolpidem, most widely used) were found with increased risk of cancers including breast cancer in two Taiwanese population-based cohort studies $(33,34)$. According to Iqbal et al. (34), it was provided based on epidemiological and bioinformatics analysis approaches that diazepam and zolpidem, but not alprazolam, might be 


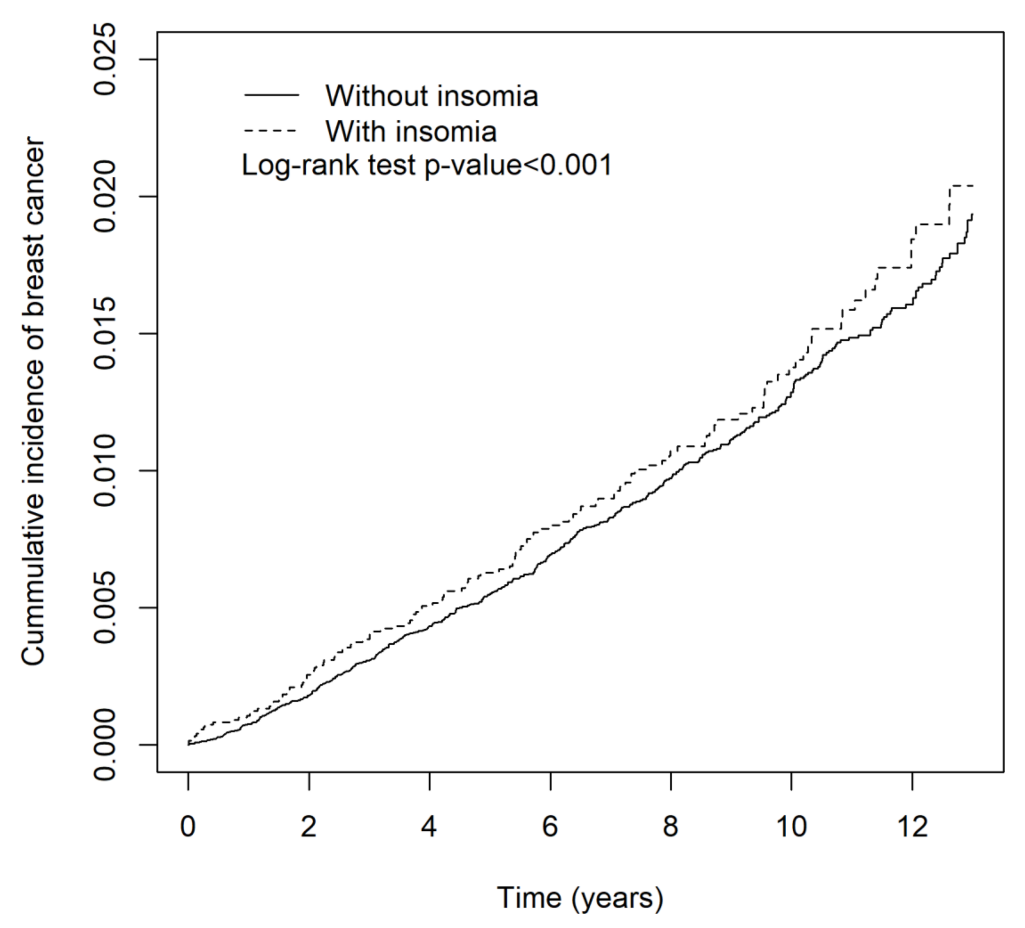

FIGURE 2 | The cumulative incidence of breast cancer in patients with and without insomnia.

associated with breast cancer risk. The underlying mechanisms between sleep medication and cancer remain obscure. Overexpression of peripheral benzodiazepine receptors (PBR) due to BZDs has been implicated in breast cancer (35), and cell proliferation was found in some breast cancer cell lines after administration of PBR agonist (36). In vitro studies, non-BZDs as zopiclone, zaleplon, and ramelteon were found clastogenic, which can lead to carcinogenesis via the process of inducing disruption or breakages of chromosomes (37).

Depressive disorders, featured by sadness or irritability, are prevalent chronic diseases with psycho-physiological symptoms (38). In breast cancer patients with comorbid anxiety and depression, a tendency of diagnosis delay beyond 90 days from symptom identification was reported. Furthermore, treatment delay of longer than 60 days from diagnosis establishment was remarkable in those with severe mental illness (39). According to Chen et al. (40), curative surgery of breast cancer was associated with increased risk of subsequent depressive disorders, and those who developed depressive disorders had higher incidence rate of tumor recurrence and mortality when followed up. There are some probable underlying mechanisms suggesting depressive disorders being carcinogenic, such as impairing immune function, giving rise to aberrancy of the hypothalamic-pituitary-adrenal axis and inhibiting DNA repair (41-43). Nevertheless, in a meta-analysis of cohort study in 2007, based on seven heterogeneous studies, showed there was no significant association between depression and subsequent breast cancer risk (44). Another recent metaanalysis of cohort study derived from 11 cohort studies in 2015 showed epidemiological evidence was insufficient to support a positive association between depression and breast cancer (45). In our study, we found a positive correlation between depressive disorders and increased incidence rate of breast cancer, but it was not statistically significant.

Mood disorders are great disease entities that include depressive disorders and bipolar disorders. Mood disorders in the Diagnostic and Statistical Manual of Mental Disorders, fourth edition (DSM-IV) have been replaced with multiple specifiers describing depressive disorders and bipolar disorders in the Diagnostic and Statistical Manual of Mental Disorders, fifth edition (DSM-V) (46). Also, DSM-IV entity of mood disorder NOS has been replaced with unspecified bipolar disorder and unspecified depressive disorder in DSM-V. To date, there were no previous studies aimed at the association between mood disorder and cancers. Since no remarkable association between bipolar disorders and breast cancer was noted in a nationwide cohort study (39), the association between depressive disorders and breast cancer was weak as mentioned above. It was hypothesized that mood disorders should be less coherent to breast cancer in that mood disorders are mainly partitioned into bipolar disorders and depressive disorders, and such inference was verified in our study, that is, mood disorders were not associated with increased hazard of breast cancer.

In high urbanization areas, in this study, the incidence rate of breast cancer in women was higher than in low urbanization areas. Also, a high insured amount was associated with increased breast cancer incidence. In a cohort study, high socioeconomic status and high income were found to have increased the incidence rate of breast cancer in the USA; however, income was not significantly correlated with mortality (47). In general, breast cancer has been regarded as a disease of affluence in risk 
TABLE 5 | The incidence rates and hazard ratios of breast cancer in depressive disorder cohort.

\begin{tabular}{|c|c|c|c|c|c|}
\hline \multirow[t]{2}{*}{ Variable } & \multicolumn{3}{|c|}{ Breast cancer } & \multirow[t]{2}{*}{ cHR $(95 \% \mathrm{Cl})$} & \multirow[t]{2}{*}{$\operatorname{aHR}^{\mathrm{a}}(95 \% \mathrm{Cl})$} \\
\hline & $\mathbf{n}$ & PY & IR & & \\
\hline \multicolumn{6}{|c|}{ Depressive disorders } \\
\hline No & 1,308 & $1,042,122$ & 1.26 & $1.00(-)$ & $1.00(-)$ \\
\hline Yes & 360 & 257,472 & 1.40 & $1.12(1.00,1.26)$ & $1.11(0.99,1.25)$ \\
\hline \multicolumn{6}{|l|}{ Age (year) } \\
\hline $20-30$ & 39 & 225,057 & 0.17 & $1.00(-)$ & $1.00(-)$ \\
\hline $30-40$ & 262 & 265,806 & 0.99 & $5.76(4.1,8.09)^{\star \star \star}$ & $5.36(3.79,7.58)^{\star \star \star}$ \\
\hline $40-50$ & 537 & 293,100 & 1.83 & $10.8(7.79,15.04)^{\star \star \star}$ & $9.71(6.93,13.6)^{\star \star \star}$ \\
\hline$>50$ & 830 & 515,631 & 1.61 & $9.68(6.99,13.4)^{\star \star \star}$ & $8.54(6.10,12.0)^{\star \star \star}$ \\
\hline \multicolumn{6}{|c|}{ Insured amount (TWD) } \\
\hline$\leq 10,000$ & 394 & 444,643 & 0.89 & $1.00(-)$ & $1.00(-)$ \\
\hline $10,000-20,000$ & 710 & 494,198 & 1.44 & $1.60(1.42,1.81)^{\star \star \star}$ & $1.10(0.97,1.25)$ \\
\hline$>20,000$ & 564 & 360,753 & 1.56 & $1.74(1.53,1.98)^{\star \star \star}$ & $1.13(0.99,1.29)$ \\
\hline \multicolumn{6}{|l|}{ Urbanization } \\
\hline Low & 93 & 94,619 & 0.98 & $1.00(-)$ & $1.00(-)$ \\
\hline Medium & 439 & 389,455 & 1.13 & $1.14(0.91,1.43)$ & $1.15(0.92,1.45)$ \\
\hline High & 1,136 & 815,520 & 1.39 & $1.42(1.15,1.75)^{\star \star}$ & $1.37(1.10,1.71)^{\star \star}$ \\
\hline \multicolumn{6}{|l|}{ Residential location } \\
\hline Northern & 843 & 598,870 & 1.41 & $1.00(-)$ & $1.00(-)$ \\
\hline Central & 353 & 301,025 & 1.17 & $0.82(0.72,0.93)^{\star \star}$ & $0.89(0.78,1.02)$ \\
\hline Southern & 161 & 150,151 & 1.07 & $0.76(0.64,0.9)^{\star \star}$ & $0.81(0.68,0.96)^{\star}$ \\
\hline Eastern & 311 & 247,579 & 1.26 & $0.89(0.79,1.02)$ & $0.95(0.83,1.09)$ \\
\hline Others & 0 & 1,970 & 0.00 & $0.00(0, \ln f)$ & \\
\hline \multicolumn{6}{|l|}{ Comorbidities } \\
\hline \multicolumn{6}{|l|}{ COPD } \\
\hline No & 1,323 & $1,065,561$ & 1.24 & $1.00(-)$ & $1.00(-)$ \\
\hline Yes & 345 & 234,033 & 1.47 & $1.24(1.1,1.4)^{\star \star \star}$ & $1.05(0.92,1.18)$ \\
\hline \multicolumn{6}{|l|}{ HTN } \\
\hline No & 1,204 & $1,017,375$ & 1.18 & $1.00(-)$ & $1.00(-)$ \\
\hline Yes & 464 & 282,219 & 1.64 & $1.44(1.29,1.6)^{\star \star \star}$ & $1.02(0.90,1.16)$ \\
\hline \multicolumn{6}{|l|}{ DM } \\
\hline No & 1,466 & $1,164,932$ & 1.26 & $1.00(-)$ & $1.00(-)$ \\
\hline Yes & 202 & 134,662 & 1.50 & $1.24(1.07,1.44)^{\star *}$ & $0.86(0.73,1.01)$ \\
\hline \multicolumn{6}{|l|}{ CKD } \\
\hline No & 1,511 & $1,199,194$ & 1.26 & $1.00(-)$ & $1.00(-)$ \\
\hline Yes & 157 & 100,400 & 1.56 & $1.27(1.07,1.49)^{\star \star}$ & $1.01(0.85,1.19)$ \\
\hline \multicolumn{6}{|l|}{ Hyperlipidemia } \\
\hline No & 1,307 & $1,102,930$ & 1.19 & $1.00(-)$ & $1.00(-)$ \\
\hline Yes & 361 & 196,664 & 1.84 & $1.63(1.45,1.83)^{\star \star \star}$ & $1.32(1.15,1.51)^{\star \star \star}$ \\
\hline \multicolumn{6}{|l|}{ Medication } \\
\hline \multicolumn{6}{|l|}{ Sleep pills } \\
\hline No & 1,008 & 903,466 & 1.12 & $1.00(-)$ & $1.00(-)$ \\
\hline Yes & 660 & 396,128 & 1.67 & $1.41(1.28,1.56)^{\star \star \star}$ & $1.39(1.26,1.54)^{\star \star \star}$ \\
\hline
\end{tabular}

${ }^{*} p$-value $<0.05 ;{ }^{* *} p$-value $<0.01 ;{ }^{* * *} p$-value $<0.001$.

PY, person-years; IR, incidence rate (per 1,000 person-years); CHR, crude hazard ratio; aHR, adjusted hazard ratio; COPD, chronic obstruction pulmonary disease; HTN, hypertension; $D M$, diabetes mellitus; CKD, chronic kidney disease.

${ }^{a}$ Adjusted by age, insured amount, COPD, HTN, DM, CKD, hyperlipidemia, and sleep pills.

factors such as delayed childbirth (48), less breastfeeding (49), and hormone supplements (50), which are more visible in affluent women. In one way, women in high socioeconomic areas have more accessibility to breast cancer screening as mammograms that detect more hidden cancer cases are highly available.

Hyperlipidemia is a status of chronic inflammation, which is a possible etiology contributing to breast cancer progression through activation of TLR signaling by oxidized LDL (51). In a hyperlipidemic mouse model, cholesterol and its metabolites have been verified to increase breast cell proliferation (52). In an observational study of 314 cases in China, elevated serum lipoprotein was associated with breast cancer (53). It is suggested that exercise could reduce the risk of hyperlipidemiaassociated breast cancer via improving chronic inflammation, lowering blood lipid level, and exerting specific anticancer effects (54). In this study, we found that hyperlipidemia was an independent risk factor for breast cancer.

\section{STUDY LIMITATION}

As this is a secondary analysis of observational data across the study period, we can only present the associations among breast 
TABLE 6 | The incidence rates and hazard ratios of breast cancer in mood disorder cohort.

\begin{tabular}{|c|c|c|c|c|c|}
\hline \multirow[t]{2}{*}{ Variable } & \multicolumn{3}{|c|}{ Breast cancer } & \multirow[t]{2}{*}{ cHR $(95 \% \mathrm{Cl})$} & \multirow[t]{2}{*}{$\mathrm{aHR}^{\mathrm{a}}(95 \% \mathrm{Cl})$} \\
\hline & $\mathbf{n}$ & PY & IR & & \\
\hline \multicolumn{6}{|l|}{ Mood disorders } \\
\hline No & 495 & 375,364 & 1.32 & $1.00(-)$ & $1.00(-)$ \\
\hline Yes & 131 & 91,702 & 1.43 & $1.09(0.90,1.32)$ & $1.11(0.91,1.34)$ \\
\hline \multicolumn{6}{|l|}{ Age (year) } \\
\hline 20-30 & 14 & 90,695 & 0.15 & $1.00(-)$ & $1.00(-)$ \\
\hline $30-40$ & 129 & 104,577 & 1.23 & $7.86(4.53,13.7)^{\star \star \star}$ & $7.30(4.16,12.8)^{\star \star \star}$ \\
\hline $40-50$ & 189 & 103,438 & 1.83 & $11.7(6.81,20.2)^{\star \star \star}$ & $10.3(5.92,18.0)^{\star \star \star}$ \\
\hline$>50$ & 294 & 168,356 & 1.75 & $11.5(6.73,19.7)^{\star \star \star}$ & $9.72(5.57,16.9)^{\star \star \star}$ \\
\hline \multicolumn{6}{|c|}{ Insured amount (TWD) } \\
\hline$\leq 10,000$ & 153 & 171,782 & 0.89 & $1.00(-)$ & $1.00(-)$ \\
\hline $10,000-20,000$ & 261 & 179,997 & 1.45 & $1.61(1.32,1.96)^{\star \star \star}$ & $1.08(0.88,1.32)$ \\
\hline$>20,000$ & 212 & 115,288 & 1.84 & $2.01(1.63,2.47)^{\star \star \star}$ & $1.24(1.00,1.54)^{\star}$ \\
\hline \multicolumn{6}{|l|}{ Urbanization } \\
\hline Low & 41 & 33,127 & 1.24 & $1.00(-)$ & \\
\hline Medium & 152 & 132,318 & 1.15 & $0.94(0.66,1.32)$ & \\
\hline High & 433 & 301,621 & 1.44 & $1.17(0.85,1.61)$ & \\
\hline \multicolumn{6}{|l|}{ Residential location } \\
\hline Northern & 314 & 222,849 & 1.41 & $1.00(-)$ & \\
\hline Central & 139 & 102,413 & 1.36 & $0.97(0.79,1.18)$ & \\
\hline Southern & 55 & 45,434 & 1.21 & $0.87(0.65,1.16)$ & \\
\hline Eastern & 116 & 95,951 & 1.21 & $0.86(0.69,1.06)$ & \\
\hline Others & 2 & 420 & 4.76 & $3.27(0.81,13.1)$ & \\
\hline \multicolumn{6}{|l|}{ Comorbidities } \\
\hline \multicolumn{6}{|l|}{ COPD } \\
\hline No & 489 & 382,740 & 1.28 & $1.00(-)$ & $1.00(-)$ \\
\hline Yes & 137 & 84,326 & 1.62 & $1.33(1.1,1.61)^{\star \star}$ & $1.11(0.91,1.35)$ \\
\hline \multicolumn{6}{|l|}{ HTN } \\
\hline No & 463 & 370,835 & 1.25 & $1.00(-)$ & $1.00(-)$ \\
\hline Yes & 163 & 96,231 & 1.69 & $1.41(1.18,1.69)^{\star \star \star}$ & $0.90(0.73,1.12)$ \\
\hline \multicolumn{6}{|l|}{ DM } \\
\hline No & 531 & 418,970 & 1.27 & $1.00(-)$ & $1.00(-)$ \\
\hline Yes & 95 & 48,096 & 1.98 & $1.63(1.31,2.03)^{\star \star \star}$ & $1.17(0.91,1.50)$ \\
\hline \multicolumn{6}{|l|}{ CKD } \\
\hline No & 569 & 431,056 & 1.32 & $1.00(-)$ & \\
\hline Yes & 57 & 36,010 & 1.58 & $1.22(0.93,1.60)$ & \\
\hline \multicolumn{6}{|l|}{ Hyperlipidemia } \\
\hline No & 486 & 397,676 & 1.22 & $1.00(-)$ & $1.00(-)$ \\
\hline Yes & 140 & 69,390 & 2.02 & $1.74(1.44,2.10)^{\star \star \star}$ & $1.33(1.06,1.66)^{*}$ \\
\hline \multicolumn{6}{|l|}{ Medication } \\
\hline \multicolumn{6}{|l|}{ Sleep pills } \\
\hline No & 379 & 331,365 & 1.14 & $1.00(-)$ & $1.00(-)$ \\
\hline Yes & 247 & 135,701 & 1.82 & $1.50(1.28,1.77)^{\star \star \star}$ & $1.53(1.30,1.80)^{\star \star \star}$ \\
\hline
\end{tabular}

${ }^{*} p$-value $<0.05 ;{ }^{* *} p$-value $<0.01 ;{ }^{* * *} p$-value $<0.001$.

PY, person-years; IR, incidence rate (per 1,000 person-years); CHR, crude hazard ratio; aHR, adjusted hazard ratio; COPD, chronic obstruction pulmonary disease; HTN, hypertension; $D M$, diabetes mellitus; CKD, chronic kidney disease.

${ }^{a}$ Adjusted by age, insured amount, COPD, HTN, DM, hyperlipidemia, and sleep pills.

cancer in Taiwanese women with insomnia, depressive disorders, mood disorders, sleep medication, insured amount, and hyperlipidemia. Also, we can only deduce cause and effect by showing that these associations are likely to be cohesive with a causal relationship between increased incidence of breast cancer and insomnia, sleep medication, high insured amount, highly urbanized areas, or hyperlipidemia. The results from this study, therefore, should be considered exploratory but preplanned and still need to be confirmed in subsequent clinical trials in the future. In this study, breast cancer, insomnia, depressive disorders, and mood disorders were based on ICD-9 codes which are replaced by ICD-10 codes currently. Because we focus on hypnotics in a general view instead of comparison of specific drugs, we could not differentiate the coefficient effect of different drugs. Routine mental illness screening is not popular in the Taiwan healthcare system. Besides, mental illnesses typically manifest years before people seek treatment (55); hence, the actual number of mental illness diagnosed before breast cancer could be underestimated, giving rise to inadequate interpretation of results.

\section{CONCLUSIONS}

In this study, women with insomnia had increased risk of breast cancer, especially those in high urbanization or with high insured 


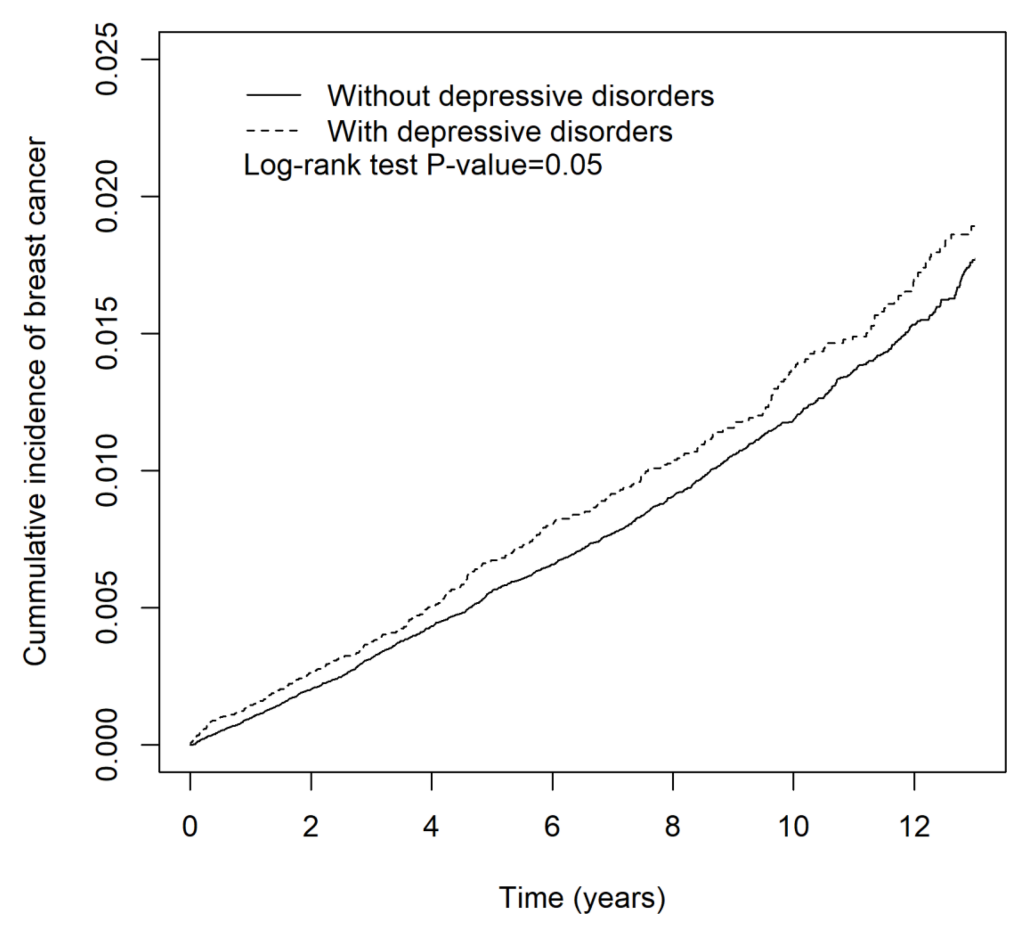

FIGURE 3 | The cumulative incidence of breast cancer in patients with and without depressive disorders.

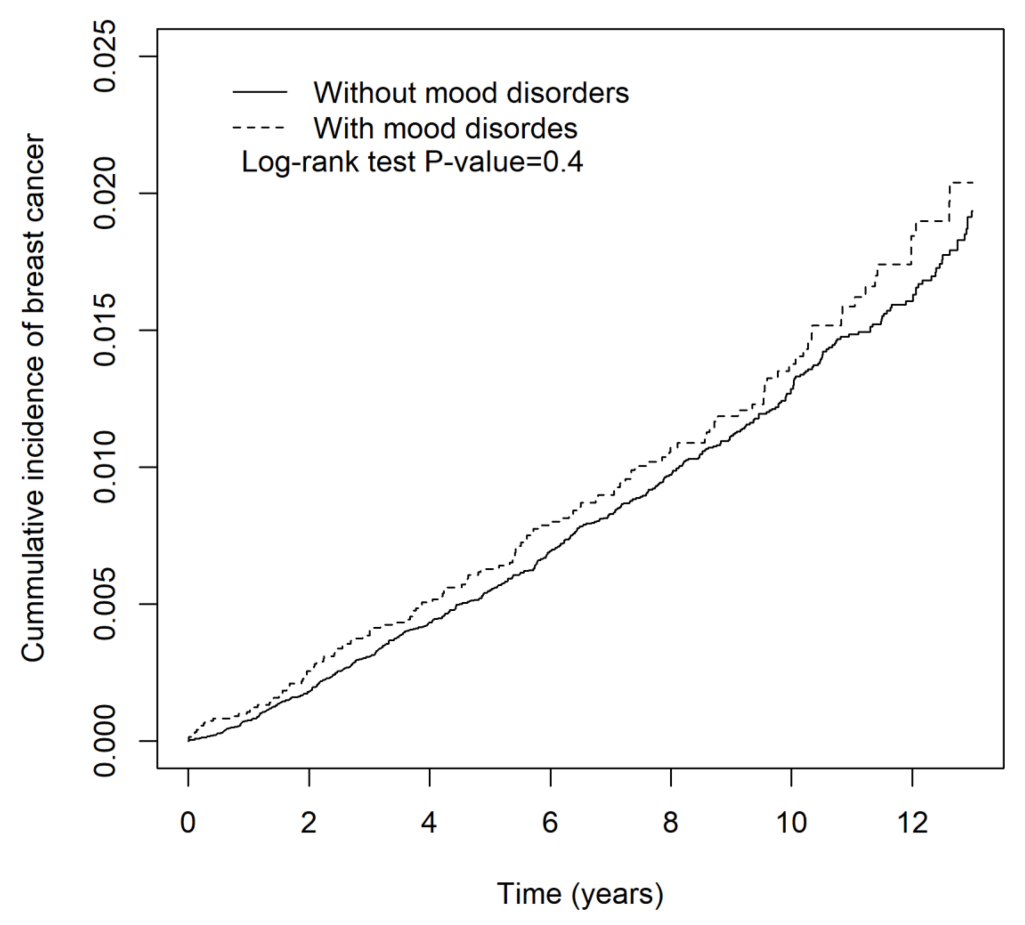

FIGURE 4 | The cumulative incidence of breast cancer in patients with and without mood disorders. 
TABLE 7 | The association of insomnia and breast cancer in different stratifications.

\begin{tabular}{|c|c|c|c|c|c|c|c|c|}
\hline \multirow[t]{2}{*}{ Variable } & \multicolumn{3}{|c|}{ Noninsomnia } & \multicolumn{3}{|c|}{ Insomnia } & \multirow[t]{2}{*}{ cHR $(95 \% \mathrm{Cl})$} & \multirow[t]{2}{*}{$\mathrm{aHR}^{\mathrm{a}}(95 \% \mathrm{Cl})$} \\
\hline & $\mathbf{n}$ & PY & IR & $\mathbf{n}$ & PY & IR & & \\
\hline \multicolumn{9}{|l|}{ Age (year) } \\
\hline $20-30$ & 24 & 130,189 & 0.18 & 23 & 127,479 & 0.18 & $1.05(0.59,1.87)$ & $1.12(0.63,2.01)$ \\
\hline $30-40$ & 147 & 179,431 & 0.82 & 192 & 174,609 & 1.10 & $1.37(1.10,1.70)^{\star \star}$ & $1.31(1.05,1.63)^{*}$ \\
\hline $40-50$ & 372 & 223,081 & 1.67 & 429 & 223,334 & 1.92 & $1.16(1.01,1.33)^{\star}$ & $1.11(0.84,1.26)$ \\
\hline$>50$ & 480 & 341,875 & 1.40 & 613 & 366,632 & 1.67 & $1.20(1.06,1.35)^{\star \star}$ & $1.17(1.04,1.32)^{*}$ \\
\hline \multicolumn{9}{|c|}{ Insured amount (TWD) } \\
\hline$\leq 10,000$ & 228 & 277,420 & 0.82 & 261 & 277,098 & 0.94 & $1.15(0.96,1.37)$ & $1.10(0.91,1.31)$ \\
\hline 10,000-20,000 & 434 & 328,620 & 1.32 & 536 & 349,531 & 1.53 & $1.16(1.02,1.32)^{\star}$ & $1.12(0.98,1,27)$ \\
\hline$>20,000$ & 361 & 268,536 & 1.34 & 460 & 265,424 & 1.73 & $1.31(1.14,1.51)^{\star \star \star}$ & $1.27(1.10,1.46)^{\star \star \star}$ \\
\hline \multicolumn{9}{|l|}{ Urbanization } \\
\hline Low & 50 & 69,996 & 0.71 & 80 & 69,815 & 1.15 & $1.69(1.18,2.41)^{\star \star}$ & $1.62(1.12,2.33)^{\star \star}$ \\
\hline Medium & 336 & 280,454 & 1.20 & 342 & 285,233 & 1.20 & $1.00(0.86,1.16)$ & $0.96(0.82,1.12)$ \\
\hline High & 637 & 524,126 & 1.22 & 835 & 537,005 & 1.55 & $1.29(1.16,1.43)^{\star \star \star}$ & $1.23(1.11,1.37)^{\star \star \star}$ \\
\hline \multicolumn{9}{|l|}{ Residential location } \\
\hline Northern & 498 & 394,530 & 1.26 & 624 & 396,026 & 1.58 & $1.26(1.12,1.42)^{\star \star \star}$ & $1.22(1.08,1.38)^{\star \star}$ \\
\hline Central & 233 & 216,425 & 1.08 & 321 & 246,668 & 1.30 & $1.20(1.01,1.42)^{\star}$ & $1.14(0.96,1.35)$ \\
\hline Southern & 117 & 103,864 & 1.13 & 137 & 96,387 & 1.42 & $1.30(1.01,1.66)^{\star}$ & $1.23(0.95,1.58)$ \\
\hline Eastern & 173 & 157,823 & 1.10 & 175 & 151,587 & 1.15 & $1.07(0.86,1.32)$ & $1.00(0.80,1.23)$ \\
\hline Others & 2 & 1,935 & 1.03 & 0 & 1,386 & 0.00 & & \\
\hline \multicolumn{9}{|l|}{ Comorbidities } \\
\hline \multicolumn{9}{|l|}{ COPD } \\
\hline No & 864 & 749,752 & 1.15 & 955 & 682,276 & 1.40 & $1.22(1.12,1.34)^{\star \star \star}$ & $1.17(1.07,1.29)^{\star \star \star}$ \\
\hline Yes & 159 & 124,824 & 1.27 & 302 & 209,777 & 1.44 & $1.12(0.92,1.35)$ & $1.12(0.92,1.36)$ \\
\hline \multicolumn{9}{|l|}{ HTN } \\
\hline No & 794 & 713,200 & 1.11 & 882 & 659,939 & 1.34 & $1.21(1.10,1.34)^{\star \star \star}$ & $1.18(1.07,1.30)^{\star \star \star}$ \\
\hline Yes & 229 & 161,376 & 1.42 & 375 & 232,114 & 1.62 & $1.13(0.96,1.34)$ & $1.11(0.94,1.31)$ \\
\hline \multicolumn{9}{|l|}{ DM } \\
\hline No & 917 & 796,971 & 1.15 & 1,074 & 784,571 & 1.37 & $1.20(1.10,1.31)^{\star \star \star}$ & $1.15(1.05,1.26)^{\star \star}$ \\
\hline Yes & 106 & 77,605 & 1.37 & 183 & 107,482 & 1.70 & $1.21(0.96,1.54)$ & $1.20(0.95,1.53)$ \\
\hline \multicolumn{9}{|l|}{ CKD } \\
\hline No & 963 & 823,377 & 1.17 & 1,133 & 803,181 & 1.41 & $1.22(1.12,1.33)^{\star \star \star}$ & $1.17(1.07,1.28)^{\star \star \star}$ \\
\hline Yes & 60 & 51,200 & 1.17 & 124 & 88,872 & 1.40 & $1.19(0.87,1.62)$ & $1.16(0.85,1.59)$ \\
\hline \multicolumn{9}{|l|}{ Hyperlipidemia } \\
\hline No & 860 & 766,579 & 1.12 & 966 & 727,336 & 1.33 & $1.20(1.09,1.31)^{\star \star \star}$ & $1.16(1.06,1.28)^{\star \star}$ \\
\hline Yes & 163 & 107,997 & 1.51 & 291 & 164,717 & 1.77 & $1.16(0.95,1.40)$ & $1.16(0.96,1.41)$ \\
\hline \multicolumn{9}{|l|}{ Medication } \\
\hline \multicolumn{9}{|l|}{ Sleep pills } \\
\hline No & 682 & 666,869 & 1.02 & 764 & 576,760 & 1.32 & $1.31(1.18,1.45)^{\star \star \star}$ & $1.27(1.15,1.42)^{\star \star \star *}$ \\
\hline Yes & 341 & 207,707 & 1.64 & 493 & 315,293 & 1.56 & $0.97(0.85,1.12)$ & $0.97(0.84,1.11)$ \\
\hline
\end{tabular}

${ }^{*} p$-value $<0.05 ;{ }^{* *} p$-value $<0.01 ;{ }^{* *} p$-value $<0.001$.

PY, person-years; IR, incidence rate (per 1,000 person-years); cHR, crude hazard ratio; aHR, adjusted hazard ratio; COPD, chronic obstruction pulmonary disease; HTN, hypertension; $D M$, diabetes mellitus; CKD, chronic kidney disease.

${ }^{a}$ Adjusted by age, insured amount, hypertension, diabetes, hyperlipidemia, and sleep pills.

TABLE 8 | The effect of sleep pills on breast cancer in insomnia cohort.

\begin{tabular}{llllll}
\hline Insomnia & Sleep pills & $\boldsymbol{N}$ & $\boldsymbol{n}$ & cHR (95\% Cl) & aHR \\
\hline No & No & $95 \%$ Cl) \\
No & Yes & 94,010 & 682 & $1.00(-)$ & $1.00(-)$ \\
Yes & No & 21,999 & 341 & $1.47(1.29,1.68)^{\star \star \star}$ & $1.46(1.28,1.67)^{\star \star \star \star}$ \\
Yes & Yes & 81,397 & 764 & $1.30(1.18,1.45)^{\star \star \star}$ & $1.28(1.16,1.42)^{\star \star \star}$ \\
\hline
\end{tabular}

${ }^{* * *} p$-value $<0.001$

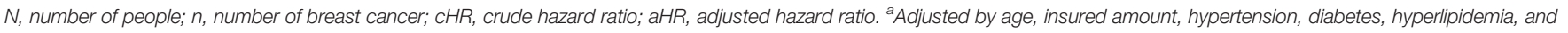
sleep pills.

amounts. Sleep medication (BZD or non-BZD) and hyperlipidemia were independently associated with a higher hazard ratio of breast cancer. Insomnia combined with sleep medication did not yield more hazard as a synergic effect. Administration of sleeping pills should be less encouraged in women, if still needed, and they should be referred to a breast cancer department for regular screening, as are those diagnosed with insomnia. Mood disorders appeared to be not associated with subsequent breast cancer. However, depressive disorders, the subgroups of mood disorders, could possibly increase the 
incidence rate of breast cancer though not statistically significant. These findings emphasize the importance of early screening of breast cancer for patients with possible risk factors. Future studies evaluating differences in breast tumor cell type, differentiation, and genotype may help target interventions.

\section{DATA AVAILABILITY STATEMENT}

The raw data supporting the conclusions of this article will be made available by the authors, without undue reservation.

\section{ETHICS STATEMENT}

The studies involving human participants were reviewed and approved by the China Medical University Hospital [CMUH104-REC2-115(AR-4)]. Written informed consent for

\section{REFERENCES}

1. Heer E, Harper A, Escandor N, Sung H, McCormack V, Fidler-Benaoudia MM. Global Burden and Trends in Premenopausal and Postmenopausal Breast Cancer: A Population-Based Study. Lancet Glob Health (2020) 8(8): e1027-37. doi: 10.1016/S2214-109X(20)30215-1

2. Siegel RL, Miller KD, Jemal A. Cancer Statistics, 2020. CA Cancer J Clin (2020) 70(1):7-30. doi: 10.3322/caac.21590

3. Potter B, Schrager S, Dalby J, Torell E, Hampton A. Menopause. Prim Care (2018) 45(4):625-41. doi: 10.1016/j.pop.2018.08.001

4. Harlow SD, Gass M, Hall JE, Lobo R, Maki P, Rebar RW, et al. Executive Summary of the Stages of Reproductive Aging Workshop + 10: Addressing the Unfinished Agenda of Staging Reproductive Aging. J Clin Endocrinol Metab (2012) 97(4):1159-68. doi: 10.1210/jc.2011-3362

5. Duijts SF, van der Beek AJ, Boelhouwer IG, Schagen SB. Cancer-Related Cognitive Impairment and Patients' Ability to Work: A Current Perspective. Curr Opin Support Palliat Care (2017) 11(1):19-23. doi: 10.1097/SPC. 0000000000000248

6. Invernizzi M, Kim J, Fusco N. Editorial: Quality of Life in Breast Cancer Patients and Survivors. Front Oncol (2020) 10:620574. doi: 10.3389/ fonc. 2020.620574

7. Sebri V, Durosini I, Triberti S, Pravettoni G. The Efficacy of Psychological Intervention on Body Image in Breast Cancer Patients and Survivors: A Systematic-Review and Meta-Analysis. Front Psychol (2021) 12:611954. doi: 10.3389/fpsyg.2021.611954

8. Nardin S, Mora E, Varughese FM, D'Avanzo F, Vachanaram AR, Rossi V, et al. Breast Cancer Survivorship, Quality of Life, and Late Toxicities. Front Oncol (2020) 10:864. doi: 10.3389/fonc.2020.00864

9. Invernizzi M, de Sire A, Lippi L, Venetis K, Sajjadi E, Gimigliano F, et al. Impact of Rehabilitation on Breast Cancer Related Fatigue: A Pilot Study. Front Oncol (2020) 10:556718. doi: 10.3389/fonc.2020.556718

10. Rogers LQ, Courneya KS, Anton PM, Verhulst S, Vicari SK, Robbs RS, et al. Effects of a Multicomponent Physical Activity Behavior Change Intervention on Fatigue, Anxiety, and Depressive Symptomatology in Breast Cancer Survivors: Randomized Trial. Psychooncology (2017) 26(11):1901-6. doi: $10.1002 /$ pon. 4254

11. Ohayon MM. Prevalence of DSM-IV Diagnostic Criteria of Insomnia: Distinguishing Insomnia Related to Mental Disorders From Sleep Disorders. J Psychiatr Res (1997) 31(3):333-46. doi: 10.1016/s0022-3956(97) 00002-2

12. Ancoli-Israel S, Roth T. Characteristics of Insomnia in the United States: Results of the 1991 National Sleep Foundation Survey. I. Sleep (1999) 22(Suppl 2):S347-53. participation was not required for this study in accordance with the national legislation and the institutional requirements.

\section{AUTHOR CONTRIBUTIONS}

Design: M-HY and JW. Acquisition of data: H-TY. Statistical analysis and interpretation: H-TY and H-PL. Manuscript writing: H-PL, JW, H-TY, and M-HY. All authors contributed to the article and approved the submitted version.

\section{ACKNOWLEDGMENTS}

We thank the National Health Insurance Administration, Ministry of Health and Welfare, and National Health Research Institutes, Taiwan, for providing access to the National Health Insurance Research Database.

13. National Institutes of Health. National Institutes of Health State of the Science Conference Statement on Manifestations and Management of Chronic Insomnia in Adults. Sleep (2005) 28):1049-57. doi: 10.1093/sleep/28.9.1049

14. Baglioni C, Battagliese G, Feige B, Spiegelhalder K, Nissen C, Voderholzer U, et al. Insomnia as a Predictor of Depression: A Meta-Analytic Evaluation of Longitudinal Epidemiological Studies. J Affect Disord (2011) 135(1-3):10-9. doi: 10.1016/j.jad.2011.01.011

15. Bolge SC, Doan JF, Kannan H, Baran RW. Association of Insomnia With Quality of Life, Work Productivity, and Activity Impairment. Qual Life Res (2009) 18(4):415-22. doi: 10.1007/s11136-009-9462-6

16. Vgontzas AN, Liao D, Bixler EO, Chrousos GP, Vela-Bueno A. Insomnia With Objective Short Sleep Duration Is Associated With a High Risk for Hypertension. Sleep (2009) 32(4):491-7. doi: 10.1093/sleep/32.4.491

17. Fang HF, Miao NF, Chen CD, Sithole T, Chung MH. Risk of Cancer in Patients With Insomnia, Parasomnia, and Obstructive Sleep Apnea: A Nationwide Nested Case-Control Study. J Cancer (2015) 6(11):1140-7. doi: 10.7150/jca.12490

18. Fann JR, Thomas-Rich AM, Katon WJ, Cowley D, Pepping M, McGregor BA, et al. Major Depression After Breast Cancer: A Review of Epidemiology and Treatment. Gen Hosp Psychiatry (2008) 30(2):112-26. doi: 10.1016/ j.genhosppsych.2007.10.008

19. Phillips KA, Osborne RH, Giles GG, Dite GS, Apicella C, Hopper JL, et al. Psychosocial Factors and Survival of Young Women With Breast Cancer: A Population-Based Prospective Cohort Study. J Clin Oncol (2008) 26(28):466671. doi: 10.1200/JCO.2007.14.8718

20. Joyce PR. Epidemiology of Mood Disorders. In: New Oxford Textbook of Psychiatry. 2 edn ed. Oxford, UK: Oxford University Press (2012). pp. 645-50. doi: 10.1093/med/9780199696758.003.0086

21. Vogtmann E, Levitan EB, Hale L, Shikany JM, Shah NA, Endeshaw Y, et al. Association Between Sleep and Breast Cancer Incidence Among Postmenopausal Women in the Women's Health Initiative. Sleep (2013) 36 (10):1437-44. doi: 10.5665/sleep.3032

22. Straif K, Baan R, Grosse Y, Secretan B, El Ghissassi F, Bouvard V, et al. Carcinogenicity of Shift-Work, Painting, and Fire-Fighting. Lancet Oncol (2007) 8(12):1065-6. doi: 10.1016/S1470-2045(07)70373-X

23. Stevens RG. Light-At-Night, Circadian Disruption and Breast Cancer: Assessment of Existing Evidence. Int J Epidemiol (2009) 38(4):963-70. doi: 10.1093/ije/dyp178

24. Fritschi L, Glass DC, Heyworth JS, Aronson K, Girschik J, Boyle T, et al. Hypotheses for Mechanisms Linking Shiftwork and Cancer. Med Hypotheses (2011) 77(3):430-6. doi: 10.1016/j.mehy.2011.06.002

25. Haus EL, Smolensky MH. Shift Work and Cancer Risk: Potential Mechanistic Roles of Circadian Disruption, Light at Night, and Sleep Deprivation. Sleep Med Rev (2013) 17(4):273-84. doi: 10.1016/j.smrv.2012.08.003 
26. He C, Anand ST, Ebell MH, Vena JE, Robb SW. Circadian Disrupting Exposures and Breast Cancer Risk: A Meta-Analysis. Int Arch Occup Environ Health (2015) 88(5):533-47. doi: 10.1007/s00420-014-0986-x

27. Ramin C, Devore EE, Pierre-Paul J, Duffy JF, Hankinson SE, Schernhammer ES. Chronotype and Breast Cancer Risk in a Cohort of US Nurses. Chronobiol Int (2013) 30(9):1181-6. doi: 10.3109/07420528.2013.809359

28. Sen A, Opdahl S, Strand LB, Vatten LJ, Laugsand LE, Janszky I. Insomnia and the Risk of Breast Cancer: The HUNT Study. Psychosom Med (2017) 79 (4):461-8. doi: 10.1097/PSY.0000000000000417

29. Contiero P, Berrino F, Tagliabue G, Mastroianni A, Di Mauro MG, Fabiano S, et al. Fasting Blood Glucose and Long-Term Prognosis of non-Metastatic Breast Cancer: A Cohort Study. Breast Cancer Res Treat (2013) 138(3):951-9. doi: 10.1007/s10549-013-2519-9

30. Villarreal-Garza C, Shaw-Dulin R, Lara-Medina F, Bacon L, Rivera D, Urzua L, et al. Impact of Diabetes and Hyperglycemia on Survival in Advanced Breast Cancer Patients. Exp Diabetes Res (2012) 2012:732027. doi: 10.1155/ 2012/732027

31. Borniger JC, Walker Ii WH, Surbhi, Emmer KM, Zhang N, Zalenski AA, et al. A Role for Hypocretin/Orexin in Metabolic and Sleep Abnormalities in a Mouse Model of Non-Metastatic Breast Cancer. Cell Metab (2018) 28 (1):118-.e5. doi: 10.1016/j.cmet.2018.04.021

32. Kryger R, Wilce PA. The Effects of Alcoholism on the Human Basolateral Amygdala. Neuroscience (2010) 167(2):361-71. doi: 10.1016/j.neuroscience. 2010.01.061

33. Kao CH, Sun LM, Liang JA, Chang SN, Sung FC, Muo CH. Relationship of Zolpidem and Cancer Risk: A Taiwanese Population-Based Cohort Study. Mayo Clin Proc (2012) 87(5):430-6. doi: 10.1016/j.mayocp.2012.02.012

34. Iqbal U, Nguyen PA, Syed-Abdul S, Yang HC, Huang CW, Jian WS, et al. Is Long-Term Use of Benzodiazepine a Risk for Cancer? Med (Baltimore) (2015) 94(6):e483. doi: 10.1097/MD.0000000000000483

35. Galiegue S, Casellas P, Kramar A, Tinel N, Simony-Lafontaine J. Immunohistochemical Assessment of the Peripheral Benzodiazepine Receptor in Breast Cancer and Its Relationship With Survival. Clin Cancer Res (2004) 10(6):2058-64. doi: 10.1158/1078-0432.ccr-03-0988

36. Akech J, Sinha Roy S, Das SK. Modulation of Cholinephosphotransferase Activity in Breast Cancer Cell Lines by Ro5-4864, a Peripheral Benzodiazepine Receptor Agonist. Biochem Biophys Res Commun (2005) 333(1):35-41. doi: 10.1016/j.bbrc.2005.05.071

37. Kripke DF. Hypnotic Drug Risks of Mortality, Infection, Depression, and Cancer: But Lack of Benefit. F1000Res (2016) 5:918. doi: 10.12688/ f1000research.8729.3

38. Benson JR, Jatoi I, Keisch M, Esteva FJ, Makris A, Jordan VC. Early Breast Cancer. Lancet (2009) 373(9673):1463-79. doi: 10.1016/S0140-6736(09) 60316-0

39. Iglay K, Santorelli ML, Hirshfield KM, Williams JM, Rhoads GG, Lin Y, et al. Diagnosis and Treatment Delays Among Elderly Breast Cancer Patients With Pre-Existing Mental Illness. Breast Cancer Res Treat (2017) 166(1):267-75. doi: 10.1007/s10549-017-4399-x

40. Chen SJ, Chang CH, Chen KC, Liu CY. Association Between Depressive Disorders and Risk of Breast Cancer Recurrence After Curative Surgery. Med (Baltimore) (2016) 95(33):e4547. doi: 10.1097/MD.0000000000004547

41. Kiecolt-Glaser JK, Robles TF, Heffner KL, Loving TJ, Glaser R. PsychoOncology and Cancer: Psychoneuroimmunology and Cancer. Ann Oncol (2002) 13(Suppl 4):165-9. doi: 10.1093/annonc/mdf655

42. Reiche EM, Morimoto HK, Nunes SM. Stress and DepressionInduced Immune Dysfunction: Implications for the Development and Progression of Cancer. Int Rev Psychiatry (2005) 17(6):515-27. doi: 10.1080/ 02646830500382102
43. Soygur H, Palaoglu O, Akarsu ES, Cankurtaran ES, Ozalp E, Turhan L, et al. Interleukin-6 Levels and HPA Axis Activation in Breast Cancer Patients With Major Depressive Disorder. Prog Neuropsychopharmacol Biol Psychiatry (2007) 31(6):1242-7. doi: 10.1016/j.pnpbp.2007.05.001

44. Oerlemans ME, van den Akker M, Schuurman AG, Kellen E, Buntinx F. A Meta-Analysis on Depression and Subsequent Cancer Risk. Clin Pract Epidemiol Ment Health (2007) 3:29. doi: 10.1186/1745-0179-3-29

45. Sun HL, Dong XX, Cong YJ, Gan Y, Deng J, Cao SY, et al. Depression and the Risk of Breast Cancer: A Meta-Analysis of Cohort Studies. Asian Pac J Cancer Prev (2015) 16(8):3233-9. doi: 10.7314/apjcp.2015.16.8.3233

46. Parker GF. DSM-5 and Psychotic and Mood Disorders. J Am Acad Psychiatry Law (2014) 42(2):182-90.

47. Lehrer S, Green S, Rosenzweig KE. Affluence and Breast Cancer. Breast $J$ (2016) 22(5):564-7. doi: 10.1111/tbj.12630

48. Panagiotopoulou K, Katsouyanni K, Petridou E, Garas Y, Tzonou A, Trichopoulos D. Maternal Age, Parity, and Pregnancy Estrogens. Cancer Causes Control (1990) 1(2):119-24. doi: 10.1007/BF00053162

49. Freudenheim JL, Marshall JR, Graham S, Laughlin R, Vena JE, Bandera E, et al. Exposure to Breastmilk in Infancy and the Risk of Breast Cancer. Epidemiology (1994) 5(3):324-31. doi: 10.1097/00001648-199405000-00011

50. Chlebowski RT, Rohan TE, Manson JE, Aragaki AK, Kaunitz A, Stefanick ML, et al. Breast Cancer After Use of Estrogen Plus Progestin and Estrogen Alone: Analyses of Data From 2 Women's Health Initiative Randomized Clinical Trials. JAMA Oncol (2015) 1(3):296-305. doi: 10.1001/jamaoncol.2015.0494

51. Hovland A, Jonasson L, Garred P, Yndestad A, Aukrust P, Lappegard KT et al. The Complement System and Toll-Like Receptors as Integrated Players in the Pathophysiology of Atherosclerosis. Atherosclerosis (2015) 241(2):48094. doi: 10.1016/j.atherosclerosis.2015.05.038

52. Hwang S, Hartman IZ, Calhoun LN, Garland K, Young GA, Mitsche MA, et al. Contribution of Accelerated Degradation to Feedback Regulation of 3-Hydroxy3-Methylglutaryl Coenzyme A Reductase and Cholesterol Metabolism in the Liver. J Biol Chem (2016) 291(26):13479-94. doi: 10.1074/jbc.M116.728469

53. Xu J, Qiu X, Li Y, Sun N, Zhang Y, Shu J. Hyperlipoproteinemia (a) is Associated With Breast Cancer in a Han Chinese Population. Med (Baltimore) (2020) 99(38):e22037. doi: 10.1097/MD.0000000000022037

54. Buss LA, Dachs GU. The Role of Exercise and Hyperlipidaemia in Breast Cancer Progression. Exerc Immunol Rev (2018) 24:10-25.

55. Wang PS, Angermeyer M, Borges G, Bruffaerts R, Tat Chiu W, E. G. G D, et al. Delay and Failure in Treatment Seeking After First Onset of Mental Disorders in the World Health Organization's World Mental Health Survey Initiative. World Psychiatry (2007) 6(3):177-85.

Conflict of Interest: The authors declare that the research was conducted in the absence of any commercial or financial relationships that could be construed as a potential conflict of interest.

Publisher's Note: All claims expressed in this article are solely those of the authors and do not necessarily represent those of their affiliated organizations, or those of the publisher, the editors and the reviewers. Any product that may be evaluated in this article, or claim that may be made by its manufacturer, is not guaranteed or endorsed by the publisher.

Copyright $\odot 2021$ Liu, Wei, Yip and Yeh. This is an open-access article distributed under the terms of the Creative Commons Attribution License (CC BY). The use, distribution or reproduction in other forums is permitted, provided the original author(s) and the copyright owner(s) are credited and that the original publication in this journal is cited, in accordance with accepted academic practice. No use, distribution or reproduction is permitted which does not comply with these terms. 